\title{
ACUARIO DE LA CORUÑA, "CASA DE LOS PECES"
}

\author{
(AQUARIUM OF LA CORUÑA, "THE FISH HOME")
}

J. Manuel Barrio y J. Miguel Valverde, Arquitectos

ESPAÑA

Fecha de recepción: 29-X-98

\section{RESUMEN}

El objeto de este proyecto es dar respuesta a los objetivos del Ayuntamiento de La Coruña en relación al concurso convocado, en base al cual, el Ayuntamiento de La Coruña tiene la voluntad de crear un complejo museístico sobre la vida marina, que se denominará "Casa de los Peces".

\section{SUMMARY}

The scope of this project is to give an actual response to the objectives the City Council of La Coruña aims by organizing a contest through which this City Council shows the interest it has on creating a museum complex on sea-life that will be called "The Fish Home".

\section{OBJETODE LA ACTUACIÓN}

\section{Soporte físico}

Se han previsto para la ubicación de la Casa de los Peces los terrenos y zona marítimo-terrestre donde estaba situada la antigua cetárea, en las proximidades de la Torre de Hércules, en As Lagoas, entre el actual Paseo Marítimo y el borde costero.

La forma del terreno resulta irregular, discurriendo entre acantilados naturales y las antiguas cetáreas, dominando el mar. Los paisajes que se observan desde este lugar hacen de él una ubicación privilegiada para establecer cualquier actividad, máxime La Casa de los Peces, que tan directa relación tiene con el mar.

\section{Necesidades a satisfacer}

Los contenidos temáticos de la Casa de los Peces versarán, primordialmente, sobre los ecosistemas de la costa gallega y los organismos que viven en ella, consiguiendo la admiración hacia las maravillas naturales más próximas. Han de verse la vida y el ambiente de los centenares de especies de seres vivos que las personas normalmente desconocen o ven sólo en el mercado.

(c) Consejo Superior de Investigaciones Científicas Licencia Creative Commons 3.0 España (by-nc)
Contendrá también una sala de exposiciones temporales, donde se podrán presentar, de diversas formas, otros temas relacionados, así como ambientes marinos y acuáticos en general de otras partes del mundo.

La instalación ocupará una superficie total de $36.000 \mathrm{~m}^{2}$. El edificio principal tendrá un máximo de $6.800 \mathrm{~m}^{2}$, de los cuales alrededor de 4.500 serán de nueva construcción, correspondiendo, el resto, a la reutilización de las instalaciones existentes.

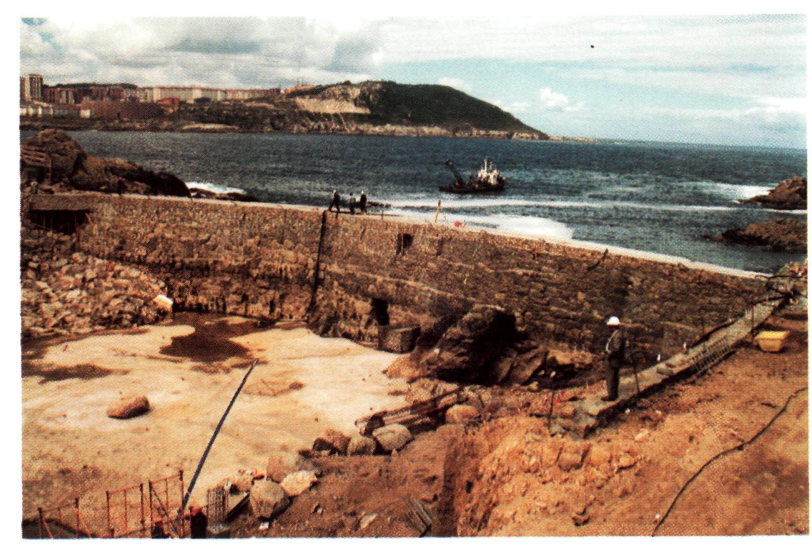

"Su situación, en As Lagoas, en un terreno irregular que domina el mar, hace que el Acuario constituya el complejo de mayor envergadura que estará dedicado al estudio de la vida y ambiente marinos". 

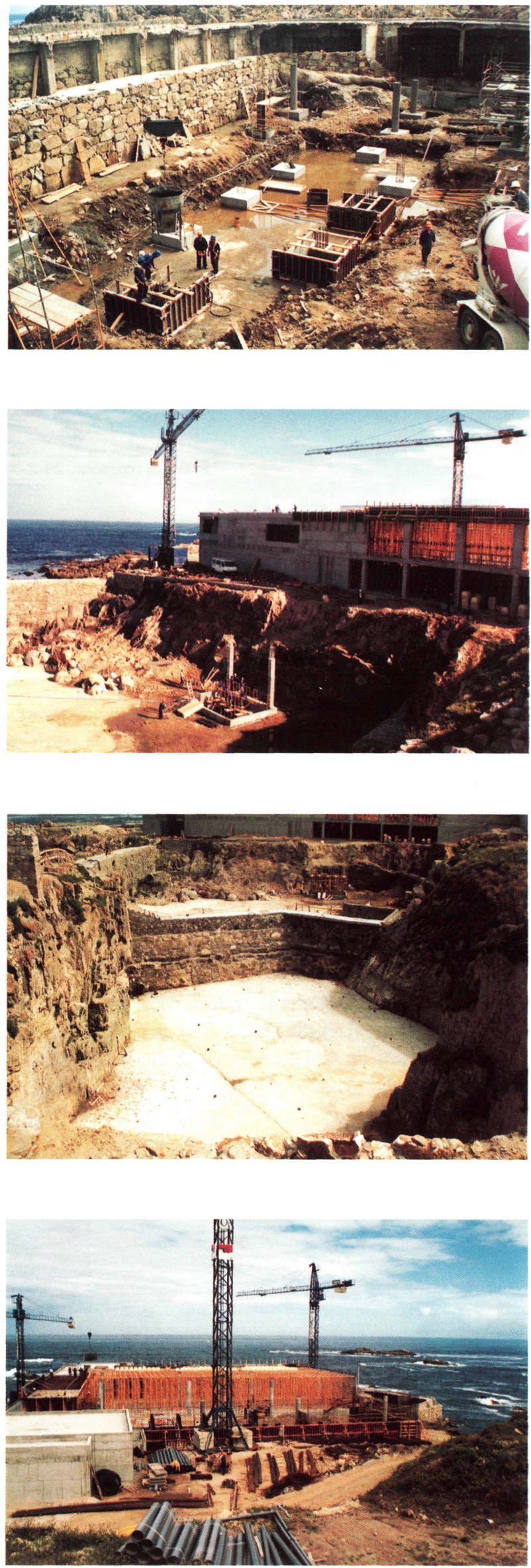

(c) Consejo Superior de Investigaciones Científicas Licencia Creative Commons 3.0 España (by-nc)
El agua de estanques y piscinas alcanzará un volumen total aproximado de 10 millones de litros. De ellos, unos 4 millones corresponden a espacios abiertos y 3,5 millones de litros a la gran piscina cubierta. Las piscinas de salas totalizarán, aproximadamente, 600.000 litros.

Es imprescindible que la instalación sea absolutamente respetuosa con la naturaleza y con los seres vivos. La sociedad es hoy especialmente crítica con los parques zoológicos, los circos y espectáculos en general que utilizan sin sentido a los animales como diversión, apartándolos de su medio natural.

Serán objeto específico de actuación, desde el punto de vista museográfico, las siguientes unidades:

\section{A)PISCINA ABIERTA ALTA}

Es la situada más hacia el sur. Se acondicionará como gran tanque de decantación para el agua a utilizar en los tanques interiores y servir como elemento paisajístico. Además, se utilizará también como espacio para la recuperación de especies de mamíferos marinos o curación de especies capturadas por embarcaciones pesqueras (tortugas, delfines,...).

\section{B)PISCINA ABIERTA BAJA}

Se acondicionará como gran espacio descubierto para la observación de la vida intermareal y las técnicas de marisqueo. Debe estar abierto a las mareas, aunque se controlará la entrada y salida de peces. Contará con zona arenosa de playa y zona rocosa. Habrá de conservar un aspecto lo más natural posible, con una vida rica en numerosas especies. Contará con la infraestructura adecuada para que lo visite el público sin que se altere el ambiente.

\section{C)TERRAZAS OBSERVACIÓNDELAROMPIENTE}

Corresponden a las zonas de aparcamiento, caminos por los bordes y cubierta de la piscina principal. Contarán con el pavimento y barandillas adecuadas para garantizar la




seguridad del público y capaces de resistir la agresión química del entorno y mecánica de las olas.

\section{D) GRAN PISCINA CUBIERTA}

Con $2.300 \mathrm{~m}^{2}$ de superficie. Se habilitará como elemento expositivo singular, con la infraestructura de visita adecuada. Capaz de albergar, al menos, 3 millones de litros de agua.

\section{E) NUEVO EDIFICIO}

Contiene las salas de exposiciones y otros espacios públi$\cos$, las oficinas, laboratorios y demás instalaciones cubiertas.

\section{SOLUCIÓN ADOPTADA}

\section{Utilización y funcionamiento del edificio}

El esquema funcional del nuevo edificio corresponde a la búsqueda de soluciones, conceptualmente sencillas, que proporcionen, al mismo tiempo, la rotundidad y la solidez que requiere un edificio de estas características.

Se pretende una arquitectura actual, tanto en lo tecnológico como en lo estrictamente formal, concebida no sólo como habitáculo donde desarrollar una serie de funciones necesarias, sino como ámbito en el que realizar actividades que vayan desde lo cotidiano a lo excepcional, huyendo de fórmulas establecidas y de actitudes miméticas que tan raras veces llegan a dar resultados positivos.

En este sentido, se entiende la arquitectura como generadora de espacios donde viviry, en este caso particular, con la dificultad añadida de relacionar las distintas formas de uso que han de darse a los diferentes espacios que el edificio alberga.

Se debe tener en cuenta la concepción del nuevo edificio de la Casa de los Peces y la actuación en la gran piscina

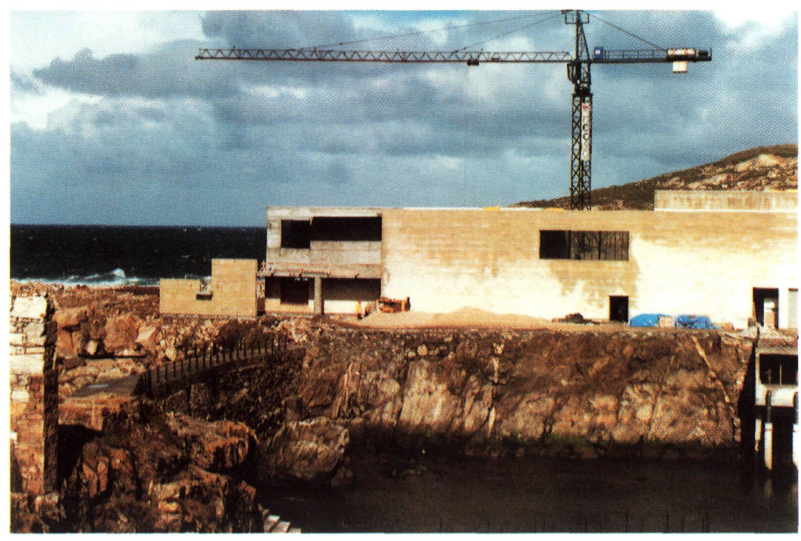

(c) Consejo Superior de Investigaciones Científicas Licencia Creative Commons 3.0 España (by-nc)
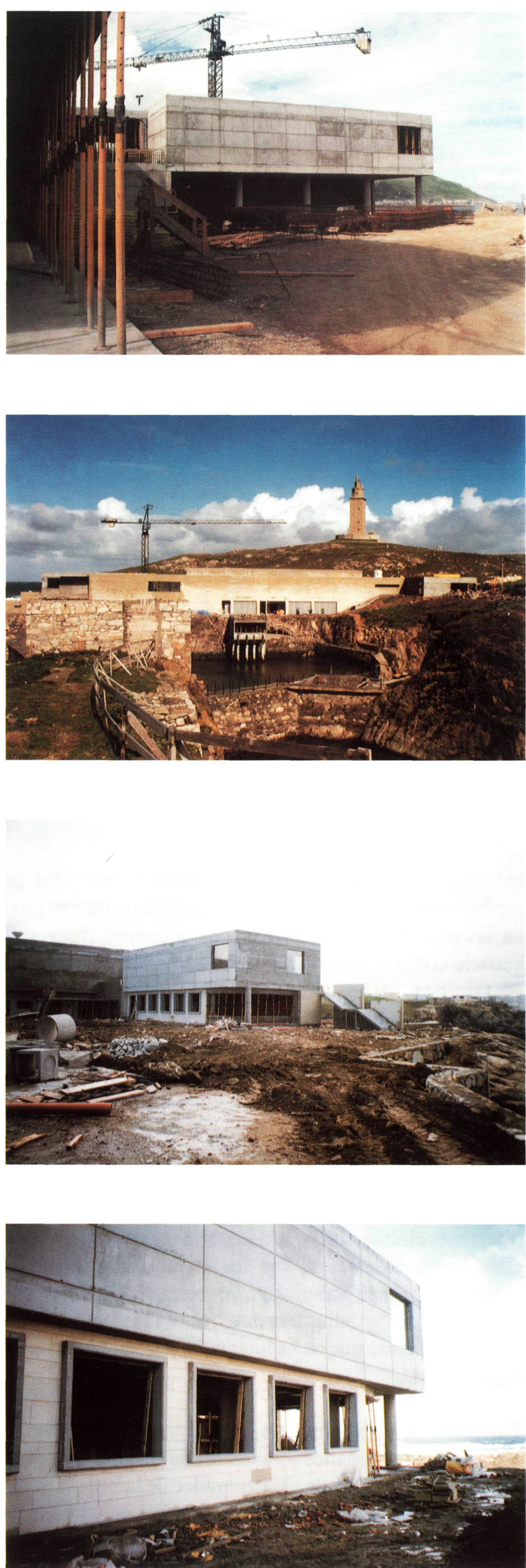


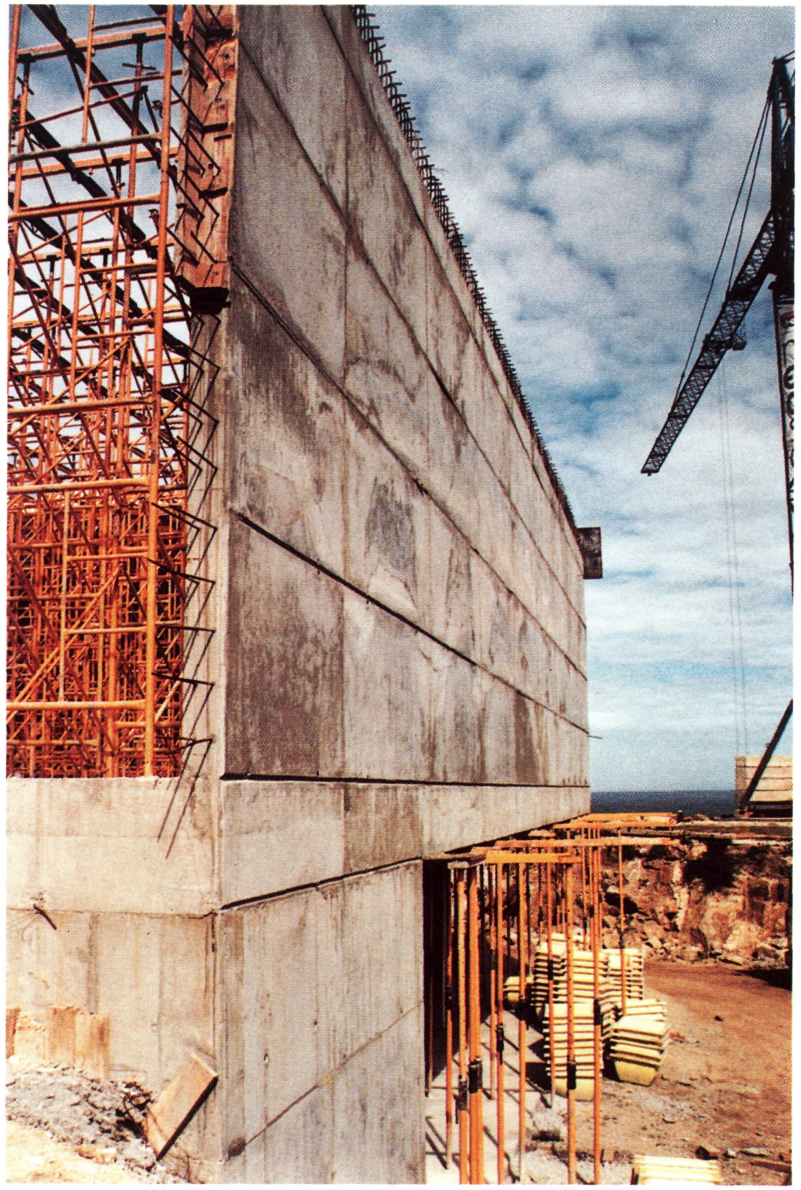

cubierta, como lugar de tránsito entre lo palpable (el medio natural del ser humano) y lo anhelable (sumergirse en las profundidades marinas), entendamos, pues, este edificio como un recinto en el que han de experimentarse sensaciones, debe ser un lugar agradable, tranquilo, sosegado, que no produzca en el visitante sentimientos excitantes, sino que sea el contenido museográfico el que produzca estos sentimientos, de manera que el edificio no desvíe la atención sobre el aspecto fundamental de la visita.

La clara separación de funciones entre los diferentes usos, la interrelación entre ellos, los conflictos creados por las diferentes circulaciones, la necesaria separación de espacios, la fragmentación, son los elementos que han de servir de base para elaborar arquitectura que no sabemos si es "inteligente" o, simplemente, resultado de un proceso de razonamiento que se ha intentado seguir con el mayor rigor posible.

Partiendo de estas premisas, se plantea una sucesión de espacios, conexionados a través de una "espina" de comunicaciones que sirve de eje generador de la intervención. Así, ésta tiene su origen en el acceso al nuevo edificio, que, a su vez, es el acceso único al recinto de todas las actividades que se desarrollarán en la Casa de los Peces, y
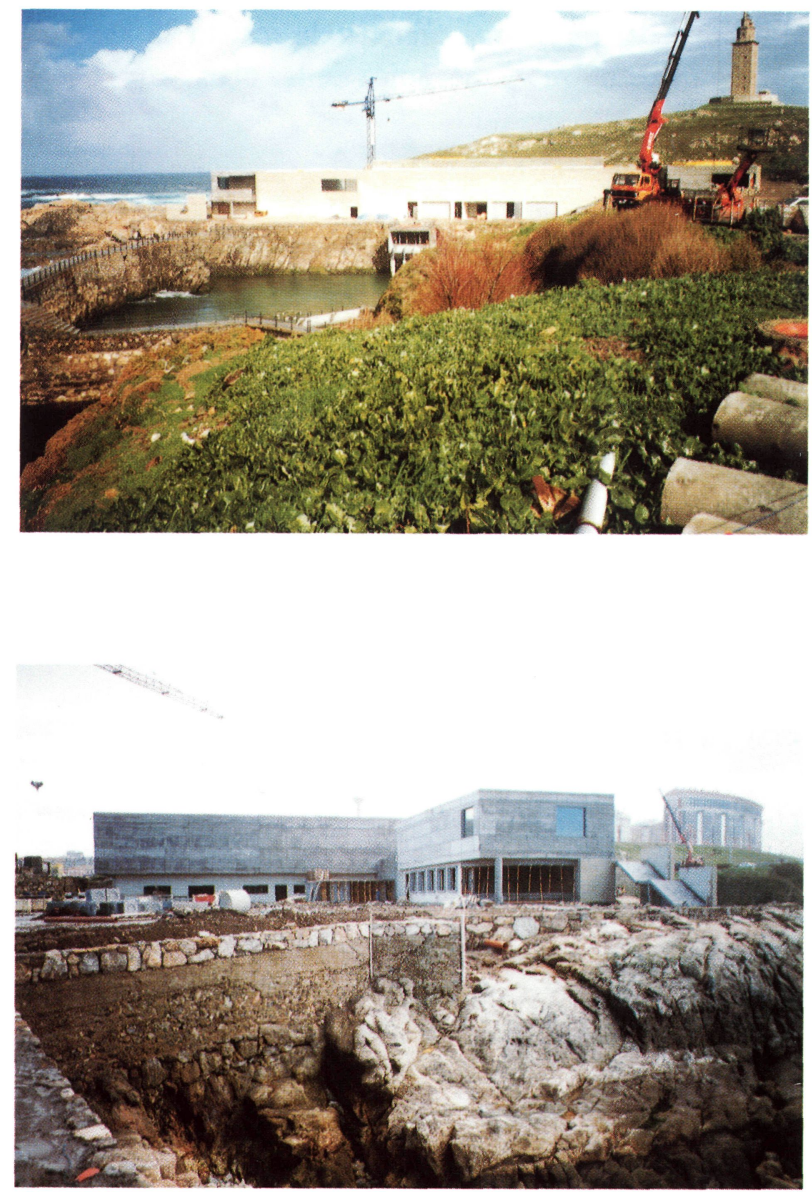

continuar en las terrazas de observación de la rompiente, para terminar, finalmente, en el hito de identificación de la Casa de los Peces que queda simbolizado por un gran chorro de agua de $50 \mathrm{~m}$ de altura, ubicado físicamente en la zona de rocas, enfrente del eje marcado por la "espina" de comunicaciones

Se ha pretendido un edificio de construcción sólida, destacando algún elemento con el empleo de materiales nobles que se integran con el entorno, granito silvestre moreno, concretamente en la "espina" de comunicaciones. El Nuevo Edificio proyectado cumple, en todo caso, los requerimientos reflejados en el Pliego de Prescripciones Técnicas del Concurso y la Normativa Municipal de aplicación, más concretamente, los aspectos reflejados en el "Plan Especial de Ordenación, Protección Conservación y Mejora de la Península de la Torre.

En general, se pretende realizar un edificio que funcione, que se convierta en contenedor neutro de usos y actividades diversas y que sea lo suficientemente moldeable como para adaptarse a los inevitables cambios que en el funcionamiento de las instalaciones museográficas se producen, sin que ello suponga modificaciones sustanciales en su concepción y tectónica iniciales. 


\section{Planteamiento museográfico}

La misión del Aquarium finisterrae es la de incrementar los conocimientos de la vida marina y su entorno, induciendo en los visitantes acciones para conservar el mundo de la mar y para tener una explotación racional de los recursos, pudiendo conseguir con los años que la costa gallega se convierta en un acuario total.

El proyecto que se propone para el Aquarium finisterrae, pretende dotar a la Ciudad de La Coruña de una instalación moderna de divulgación y ocio científico, en la línea de la "Casa de las Ciencias" y la "Casa del Hombre" y que tenga como objetivo la formación del público de la Ciudad de La Coruña y demás visitantes, acerca de la importancia y la belleza de las personas, la geografía, la vida y las especies que componen el mundo marino de la zona de Finisterre.

Dado el planteamiento divulgativo del Acuario, el mismo estará dirigido a ciudadanos de todas las edades y, a través de él, se estimulará el interés por el conocimiento y la conservación del medio ambiente marino, las costas de Finisterre, los oficios del mar, etc.

Las técnicas museográficas empleadas en el proyecto permiten aplicar las más modernas formas de divulgación, para, de esta manera, facilitar una visita lúdica, a la vez que formativa, del Acuario, siempre de una manera respetuosa con la naturaleza y con los seres vivos, sin entrar en la creación de una especie de "Sea World", donde los animales son tratados como protagonistas forzados de un espectáculo.

La ubicación geográfica del Aquarium finisterrae, única en el mundo, permitirá gozar de la inmensidad del océano, ya que su situación es un mirador único para contemplar el mar en calma, el mar embravecido, los barcos que pasan por delante del Acuario, así como las bandadas de delfines, vuelos de gaviotas, ostreros, limícolas, etc.

Estas mismas características de emplazamiento permiten asegurar que en el Acuario se podrán observar la gran mayoría de especies de la zona, ya que además de las especies capturadas, una parte de los acuarios están abiertos directamente al mar, lo que comporta la rápida colonización de especies animales y vegetales, así como de microorganismos autóctonos. Toda la flora y fauna intermareal estará perfectamente presente en los recintos exteriores.

Las especies presentes en el Acuario son autóctonas y obtenidas directamente por pescadores de la zona que hacen salidas específicas para dotar de población a Acuario. Los visitantes del Acuario, podrán observar en vivo aquellas especies de peces que, habitualmente, sólo conocen en el plato de la mesa o en los mercados centrales. Pero no sólo conocerán estas especies comercializadas, sino buena parte de aquellas otras que conviven con las primeras pero que no son comercializadas y que, muchas veces, son las que permiten su existencia. Además, podrán observarlas en una reproducción del entorno real en el que se desenvuelven.

Los acuarios que albergarán a las diferentes especies serán tratados como elementos ecológicamente homogéneos, con el objetivo de enseñar y divulgar los diferentes hábitats que forman el mar en la zona de Finisterre. Cada uno de ellos será fiel reflejo de la realidad, ya que las escenografías utilizadas en los mismos reproducirán los ambientes en los que se encuentran cada una de las especies. La utilización mayoritaria de la luz natural para su iluminación, planteada desde un primer momento como condición para respetar las estaciones del año en los habitantes del Acuario, permitirá observar los ciclos naturales de las diferentes especies a lo largo del año para, de esta manera, perturbar, lo menos posible, las condiciones naturales del exterior.

Esta característica se ve confirmada por la utilización en el sistema de tratamiento de agua del Acuario, agua obtenida directamente del mar. Únicamente filtrada por medio de filtros físicos, lo que permite incorporar al interior del mismo los nutrientes naturales habituales que se encuentran en suspensión en el océano, a la temperatura correcta para la estación del año, y con la salinidad real que le corresponde.

La reutilización de la cetárea cubierta propone un espacio único, con más de tres millones de litros de agua de mar, permitiendo disponer de especies autóctonas de más de 100 kilos de peso, en condiciones óptimas para una observación, pretendiéndose, al mismo tiempo, que sea espectacular y que cree un recuerdo imborrable de la visita.

Asimismo, el Acuario dispone de una sala especial anexa en la que se desarrollarán exposiciones temporales, que tratarán de temas también relacionados con el mar y sus habitantes, pero, que en ocasiones, pueden ser de mares tropicales lejanos, así como profesiones, etc La temática de esta sala de exposiciones temporales puede ser tan amplia como se desee y, a modo de ejemplo, pueden ser citadas desde las migraciones de diferentes especies, los mamíferos marinos, los tiburones y el remonte de angulas, hasta los bancos de cigalas, los cortejos de distintas especies, la merluza y su influencia económica, la vida de los marineros en los pesqueros, ya sean grandes o pequeños, las esposas del mar, la otra orilla, etc.

\section{DESCRIPCIÓN CONSTRUCTIVA DE LASOBRAS}

\section{NUEVOEDIFICIO}

\section{Planta de acceso}

Es la planta de exposiciones, en ella se sitúan la sala de exposiciones permanentes, donde se ubicarán las piscinas 
-con capacidad para 500.000 litros de agua- además del resto de elementos expositivos, tal y como se refleja en los planos, la sala de exposiciones temporales, vestíbulo de acceso, tienda, guardarropa, aseos públicos y el pasillo -"espina"- de comunicaciones, entre los diferentes elementos.

\section{Cerramientos}

Con el objeto de obtener un muro de cierre que se comporte armónicamente ante la lluvia y que constituya una barrera con buen comportamiento térmico y acústico, se adopta una pared compuesta de dos hojas con aislante térmico intermedio. La hoja exterior estará compuesta por un muro de hormigón de $20 \mathrm{~cm}$ de espesor, con la modulación y diseño reflejado en los planos de alzados y acabado arquitectónico, presentando una textura de gran calidad superficial. La hoja interior estará formada por fábrica de bloques de hormigón de $10 \mathrm{~cm}$ de espesor, enfoscada y acabada con pintura acrílica plástica en colores oscuros. Entre ambas hojas se situará un aislamiento térmico de poliestireno expandido de $6 \mathrm{~cm}$ de espesor, o poliuretano proyectado de $3 \mathrm{~cm}$ de espesor, según los casos.

En el pasillo -“espina"- de comunicaciones se dispone un acabado superficial exterior que lo diferencia del resto de elementos, a base de aplacado de granito silvestre moreno en piezas de $3 \mathrm{~cm}$ de espesor.

\section{Particiones interiores}

Por el propio diseño arquitectónico del conjunto, prácticamente no existen particiones interiores. Éstas se consiguen con los propios elementos expositivos que conforman ambientes y recorridos. No obstante, las particiones existentes se resuelven con fábrica de bloques de hormigón de diferentes espesores y acabadas, bien enfoscadas y pintadas, bien con revestimiento de plaqueta cerámica, según los usos de los locales donde se ubican.

\section{Vidrios}

Las zonas de visión dispuestas en los cerramientos exteriores, se resolverán con un doble acristalamiento dotado de un alto grado de aislamiento térmico, con un factor $\mathrm{K}=1,7 \mathrm{~W} /{ }^{\circ} \mathrm{C} \mathrm{h} \mathrm{m} \mathrm{m}^{2}$, transmisión energética del $37,5 \%$, reflexión energética del 28,8\% y factor solar de 43 . Este acristalamiento ha sido calculado para un presión de viento de $80 \mathrm{~kg} / \mathrm{m}^{2}$, equivalente a una velocidad de viento de $130 \mathrm{~km} / \mathrm{h}$.

\section{Revestimientos interiores}

El revestimiento de las salas de exposición y circulación se realizará con pintura acrílica, en colores oscuros mate sobre enfoscado de mortero de cemento. En aseos el revestimiento será de plaqueta cerámica de alta calidad. Los techos, que no disponen de falso techo, se terminarán con pintura acrílica en colores mate, similares a las paredes.

\section{Pavimentos}

Los pavimentos dispuestos tratan de estructurar el espacio apoyándose en materiales, texturas y modulaciones. De esta manera tanto las circulaciones a través del eje principal como las circulaciones del recorrido principal en la sala de exposiciones permanentes se diferencian con un pavimento de granito silvestre moreno acabado apomazado de $4 \mathrm{~cm}$ de espesor en módulos de 1,20x1,20 m, formados por piezas de granito de $0,60 \times 0,60 \mathrm{~m}$. Las rampas de circulación y comunicación entre los diferentes niveles de esta planta se pavimentan con granito silvestre moreno acabado abujardado de $4 \mathrm{~cm}$ de espesor y modulación de $0,60 \times 0,60 \mathrm{~m}$.

En las zonas de exposición, tienda y taquillas-guardarropa, dado que el espacio estará ocupado, en gran parte, por los acuarios y demás elementos expositivos, se dispone un pavimento de características menos nobles aunque de una gran calidad constructiva. Esto es así con el empleo de un pavimento vinílico homogéneo de bajo mantenimiento, de $2,00 \mathrm{~mm}$ de espesor, peso de $3,1 \mathrm{~kg} / \mathrm{m}^{2}$, pérdida de grosor por abrasión, según DIN 51963, de 0,15 mm. Protegido con una capa de poliuretano flexible para eliminar el poro microscópico.

\section{Techos}

En general no se dispone falso techo en las salas de exposición. Éste presentará la estructura vista pintada al clorocaucho en negro mate, con las instalaciones dispuestas regularmente y perfectamente moduladas, La instalación de aire acondicionado, que por su volumen es la más importante visualmente, dispondrá sus canalizaciones acabadas en aluminio y pintadas en negro mate de manera que se confunda con el techo.

En la zona de acceso y pasillo de comunicaciones, por su menor altura y densidad de instalaciones, se dispondrá un falso techo de rejilla -fabricado en aleación de aluminio-, en color gris grafito

En la zona de aseos se dispone un falso techo registrable de placas de escayola.

\section{Planta semisótano}

Es la planta de servicios y de conexión con las instalaciones dispuestas en la gran piscina cubierta, en ella se sitúan, además, la zona de cafetería, pic-nic, el aula, sala de proyecciones y el vestíbulo de conexión entre las circulaciones procedentes de la planta superior con las activida- 
des públicas que se dan en esta planta y las que se posibilitan a través de ésta. En el resto de la planta se dispone la zona de oficinas, el área de mantenimiento biológico y laboratorios, taller y almacén de mantenimiento general, zona de depuración de aguas de las piscinas ubicadas en el edificio, sala de control de instalaciones y cuartos para centro de transformación, grupo electrógeno y equipos de aire acondicionado. Se disponen, asimismo, los correspondientes grupos de aseos para el público y vestuarios de personal, duchas y cuartos de limpieza.

Asimismo se disponen 2 ascensores. Uno de comunicación con la planta del nivel de accesos y otro de comunicación con la gran piscina cubierta de manera que en todos los casos esté resuelta la circulación para personas con algún tipo de minusvalía y dar, al mismo tiempo, cumplimiento a la normativa sobre supresión de barreras arquitectónicas.

\section{Cerramientos}

Los muros de cierre no estructurales, que se encuentran retranqueados respecto de la línea de fachada y, por lo tanto, protegidos de la acción directa de la lluvia, se resolverán con una pared compuesta de dos hojas con aislante térmico intermedio. La hoja exterior estará compuesta por un muro de fábrica de bloques de hormigón de $20 \mathrm{~cm}$ de espesor aplacado de granito silvestre moreno en piezas de $2 \mathrm{~cm}$ de espesor, con la modulación y diseño reflejado en los planos de alzados, y acabado. La hoja interior estará formada por fábrica de bloques de hormigón de $10 \mathrm{~cm}$ de espesor, enfoscada y acabada con pintura acrílica plástica, en colores oscuros. Entre ambas hojas se situará un aislamiento térmico de poliestireno expandido de $6 \mathrm{~cm}$ de espesor.

En la proyección del pasillo -“espina"- de comunicaciones se dispondrá el mismo acabado superficial que en la planta superior.

\section{Particiones interiores}

Como regla general todas las particiones interiores de esta planta se resuelven mediante fábrica de bloques de hormigón de $15 \mathrm{~cm}$ de espesor, enfoscado por ambas caras y teniendo diferentes acabados superficiales en función del tipo de sala y la función que desempeñe. Estos acabados se encuentran perfectamente reflejados en los planos de este proyecto de ejecución.

\section{Vidrios}

Por lo que respecta a las zonas de visión, al igual que en la planta de acceso, serán resueltas también con un doble acristalamiento de alto grado de aislamiento térmico, con el mismo factor. Los valores de transmisión y reflexión energética, así como el factor solar, serán los mismos.

\section{Revestimientos interiores}

Los revestimientos, en general, serán a base de pintura acrílica en colores, según el tipo de sala, en las zonas de público serán colores mate y, en las zonas de servicios del edificio, serán en colores claros acabado satinado. En la sala de depuración, C.T., G.E. y aire acondicionado se aplicará pintura al clorocaucho directamente sobre la fábrica de bloques de hormigón, perfectamente rejuntada en disposición de "cara vista". En aseos el revestimiento será de plaqueta cerámica de alta calidad. Los techos, que no disponen de falso techo, se terminarán con pintura acrílica en colores mate, similares a las paredes.

\section{Pavimentos}

Los pavimentos se disponen con el criterio de la planta superior, en función del uso de cada una de las estancias y diferenciando si su ubicación es interior o exterior. De esta manera en las zonas de acceso libre de los visitantes se dispone el aplacado con pavimento prefabricado pétreo fabricado con árido micrograno prensado al vacío, en piezas de 0,60x0,60 $\mathrm{m}$ y acabado apomazado.

En la zona de oficinas y pasillo de circulación interior se prevé terrazo microchina prensado al vacío, en piezas de $40 \times 40 \mathrm{~cm}$.

En la zona de mantenimiento biológico y laboratorios se prevé un acabado de la solera con pintura de poliuretano, de gran resistencia al desgaste y dureza.

\section{GRAN PISCINA CUBIERTA}

En la solución de este espacio se plantea la creación de un observatorio por debajo del nivel del agua en el interior de la cetárea, de manera que se pueda observar la vida marina tal y como la ve el pez, "desde dentro", con sus contraluces y perspectivas.

Ello será así a través de la creación de un recinto acristalado en toda su superficie de paramentos verticales, donde el nivel del agua se situará por encima de la cota máxima del acristalamiento de paredes, provocando una turbulencia en su superficie para no tener visión desde dentro del observatorio del resto del recinto de la cetárea. El volumen de agua que se dispondrá será de 3 millones de litros aproximadamente. Dado el perfil orográfico del interior de la cetárea actual, la cota de agua, para conseguir el volumen mencionado, alcanzará los 3,50 m de altura sobre el nivel del suelo de ésta. Esto es así dado que existen en su interior promontorios rocosos que ocupan un gran volumen y que impiden que toda la superficie de forjado de cobertura del espacio de la cetárea, correspondiente con la superficie de fondo de ésta, tenga un perfil aproximadamente horizontal. 


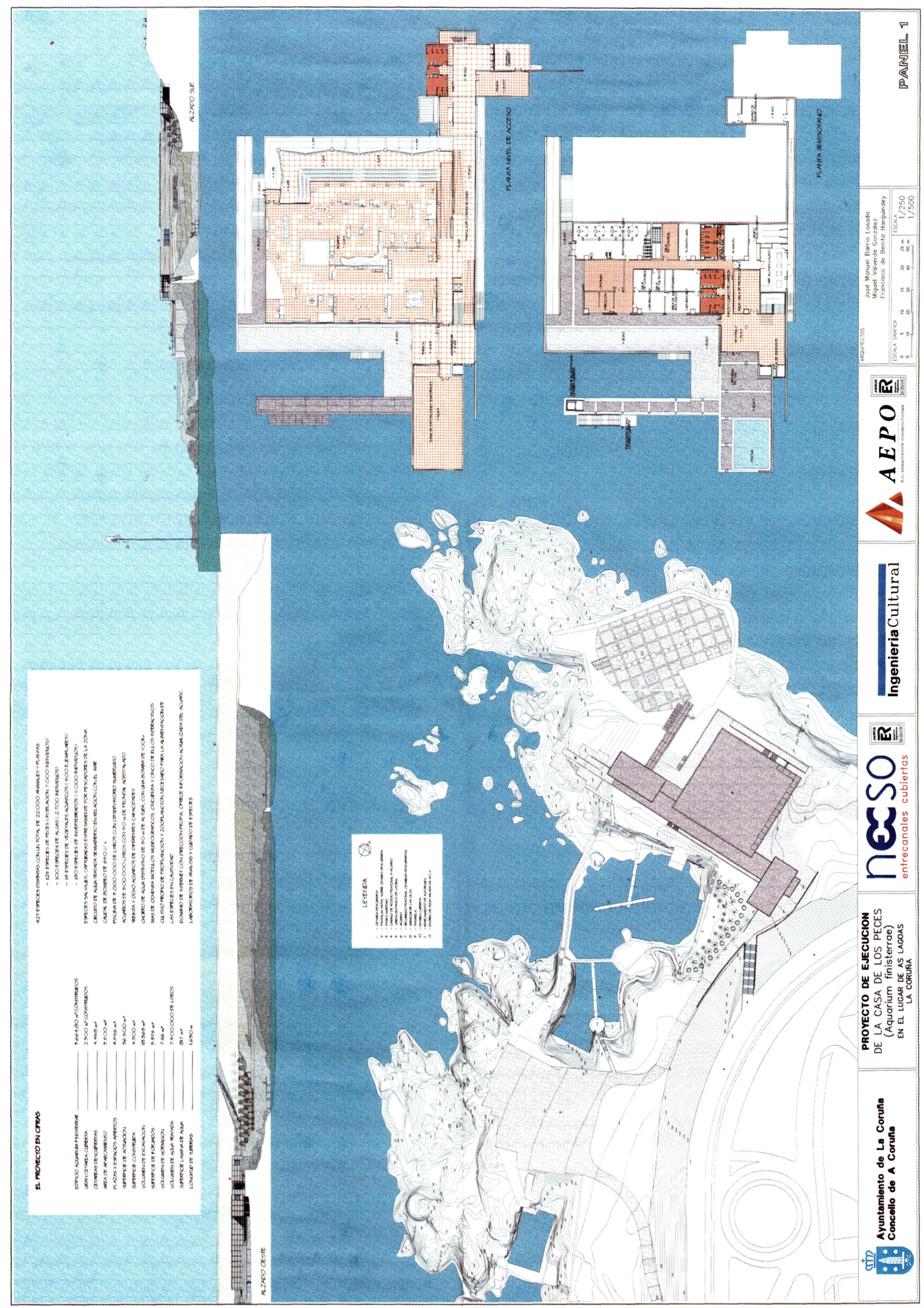




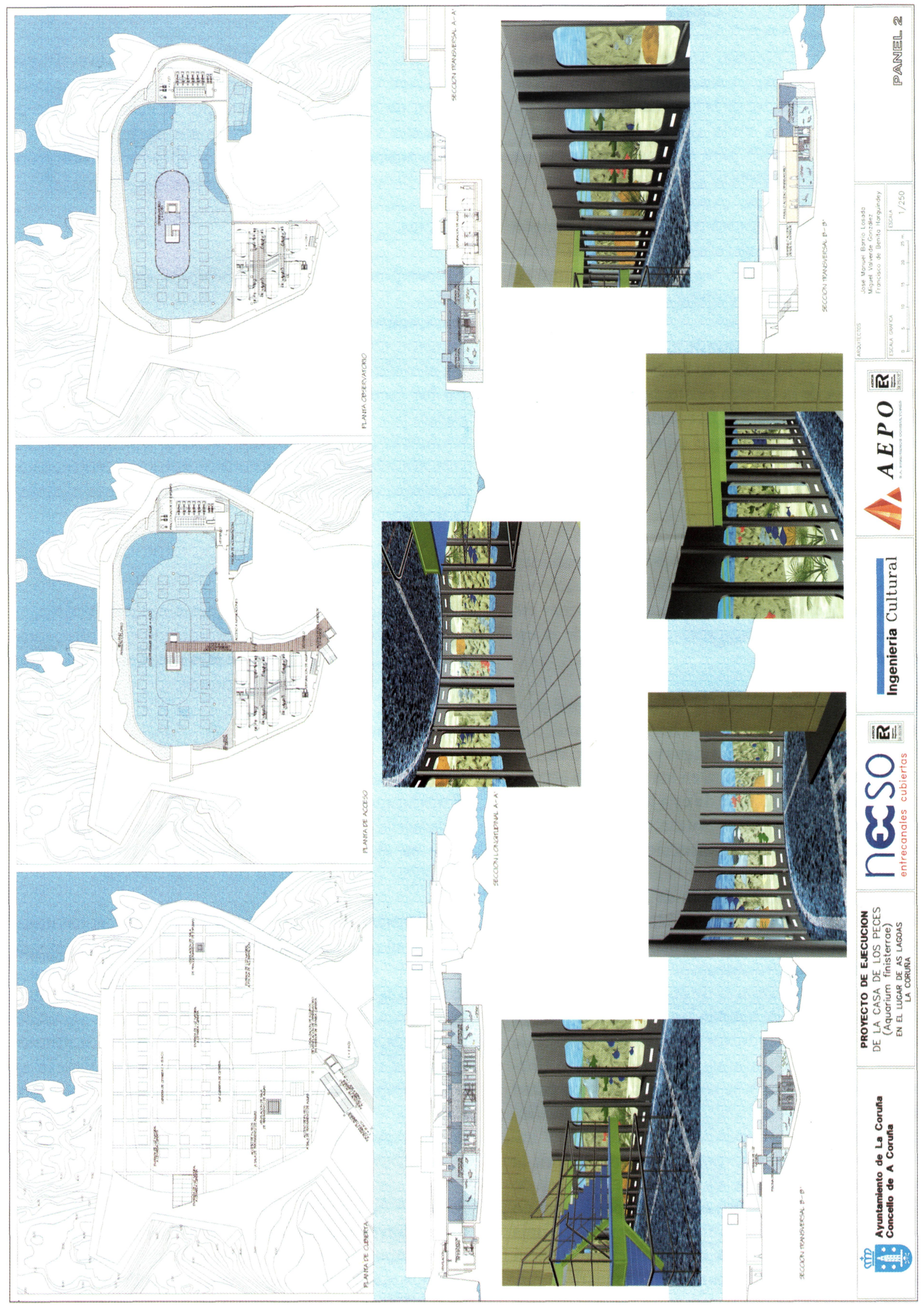


Con el nivel de agua alcanzado, equivalente a la cota $+4,00$ sobre el nivel del mar en la bajamar $(0,00)$, se compensa el empuje de agua en la pleamar, según los datos de mareas de La Coruña. Aun así, y para contener el volumen de agua dispuesta en el interior de la cetárea se construirá un muro perimetral, en la zona donde se ubica éste, dimensionado lo suficiente para soportar esta carga de agua cuando el nivel de marea se encuentra en la bajamar. Entre este muro y el muro existente de la cetárea en contacto con el mar se colocará un relleno de hormigón "ciclópeo" de manera que se refuerce el muro existente, creando un gran contrafuerte, hasta el nivel máximo de mareas, capaz de soportar el empuje de las olas.

Igualmente se disponen las áreas de tratamiento de aguas, para el volumen de 3 millones de litros, que ocupan dos salas en el interior de la cetárea existente, una para ubicación de los filtros y otra para el fraccionador de espumas. Asimismo se ubica una sala que alberga la piscina de aclimatación de peces.

\section{Cerramientos}

Ya que se trata de una construcción existente, el volumen de actuación está definido. De esta manera las actuaciones que se realizan son tendentes a mejorar o subsanar las deficiencias que presenten algunos elementos de la estructura y cierre superior.

En cuanto al forjado de superficie se prevé, en este proyecto, su sustitución por una losa de hormigón armado de $20 \mathrm{~cm}$ de espesor, apoyada en las vigas y pilares existentes y unidos a éstas según se muestra en los planos de estructura de la cetárea. La capacidad de esta losa se prevé para una sobrecarga de $500 \mathrm{~kg} / \mathrm{m}^{2}$, según marca la normativa en vigor para espacios de reunión y espectáculos sin asientos.

Los muros de cierre de las salas de instalaciones de tratamiento de aguas, sala de filtros y sala de fraccionador de espumas, deberán tener un fuerte aislamiento acústico para evitar que el ruido, procedente de los motores en ellas ubicados, se traslade al espacio de acceso de visitantes y al volumen de agua donde habitan las especie marinas, ya que el agua es un buen conductor del sonido y, el ruido de los motores, de manera continua, puede perturbar o afectar su vida. De esta manera se resolverán con una pared compuesta de dos hojas con aislante acústico intermedio. La hoja interior, a la zona de público, se resolverá mediante muro de hormigón armado por debajo del nivel de la lámina de agua y con muro de fábrica de bloques de hormigón de $20 \mathrm{~cm}$ de espesor, enfoscado por la cara de exposición y pintura acrílica color negro mate. La hoja exterior, la que da a las salas de instalaciones, estará formada también por muro de fábrica de bloques de hormigón de $20 \mathrm{~cm}$ de espesor con la cara vista hacia el interior de las salas de equipos de tratamiento de aguas. Entre ambas hojas se situará un aislamiento acústico a base de plancha de corcho de $10 \mathrm{~cm}$ de espesor.

\section{Particiones interiores}

Todas las divisiones interiores del interior de la cetárea se resuelven mediante fábrica de bloques de hormigón de $20 \mathrm{~cm}$ de espesor, enfoscado por la cara de visión de visitantes y pintado en colores mate con pintura acrílica. Estos acabados se encuentran perfectamente reflejados en los planos de este proyecto de ejecución.

\section{Vidrios}

La composición de los paramentos acristalados o de visión se ha previsto a base de láminas de metacrilato en masa, con una superficie visual de $2,60 \times 1,00$ m aproximadamente, con apoyos en el perímetro a través de rebajes en los elementos de hormigón que componen el paramento. En los lucernarios se dispone un acristalamiento compuesto por vidrio de seguridad $6+6+6 \mathrm{~mm}$ unidos con 2 láminas de butiral entre cada 2 vidrios. Uno de los vidrios será armado y una de las láminas de butiral será traslúcida, blanca, para evitar la visión del interior desde la cubierta de la cetárea.

\section{Revestimientos interiores}

Los revestimientos, en general, serán pintura acrílica en colores, según el tipo de sala, en las zonas de público serán colores mate y en las zonas de servicios del edificio serán en colores claros, acabado satinado.

\section{Pavimentos}

Los pavimentos dispuestos procuran ser coherentes con el medio en el que se disponen, por ello se procura utilizar un material en consonancia con mar como es la madera de teca, en el espacio de recepción y de traslado de los visitantes hasta el interior del "observatorio".

En el interior del "observatorio", se dispone un pavimento de gran resistencia al desgaste, pero, a la vez, cómodo al "sentir" del observador, ya que, dadas las características de la sala la percepción del pavimento, no se realizará con la vista. Por ello se ha elegido un pavimento agradable a la pisada, no resbaladizo, de gran resistencia a la abrasión y fácil de mantener para conservarlo limpio. Esto es así con el empleo de un pavimento vinílico homogéneo de bajo mantenimiento, de 2,00 $\mathrm{mm}$ de espesor. Protegido con una capa de poliuretano flexible, para eliminar el poro microscópico.

Sobre la cubierta de la cetárea (terraza) se dispone el mismo pavimento que en las zonas exteriores de la planta semisótano, es decir, pavimento de hormigón lavado, dejando el árido de granito visto, con bandas de pavimento prefabricado pétreo realizado con árido micrograno prensado al vacío, en piezas de $0,60 \times 0,60 \mathrm{~m}$ y acabado apomazado, según la disposición y diseño reflejado en los planos. 


\section{RESUMEN DE LAS ACTUACIONES MUSEOGRÁ- FICAS}

Algunos hechos y cifras que describen este proyecto sobre el "Aquarium finisterrae" son los siguientes:

En total hay presentes, de forma controlada y censada, 427 especies distintas, con un total de 22.000 animales y plantas.

Hay unas 125 especies de peces, con una población de 7.000 animales. Hay más de 100 especies de algas con unos 2.700 individuos. Hay unas 15 especies de vegetales acuáticos, con unos 500 ejemplares. Y, finalmente, hay más de 190 especies de invertebrados, con una población de más de 11.000 individuos.

Más de 9.000 individuos están presentes en los acuarios interiores, mientras que en la charca intermareal exterior se concentra el resto, siendo, lo más probable, que esta cifra se vea incrementada fácilmente.

Todas las especies que se presentan, a excepción del apartado de piscifactorías, son especies salvajes, no procedentes de granja, facilitadas por pescadores de la zona que las han cogido especialmente para el Acuario.

Existe un plan especial de capturas y acondicionamiento de especies que se prolonga durante un año y que finaliza tres meses antes de la inauguración.

Tres meses antes de inaugurar, los acuarios empezarán a ser colonizados con las especies y los ejemplares correspondientes. Y funcionarán con los equipos definitivos de tratamiento de aguas.

La capacidad total del Acuario es de unos ocho millones de litros de agua de mar. De estos ocho millones de litros, tratamos y acondicionamos unos tres millones y medio.

El circuito de acondicionamiento y tratamiento es semiabierto, coge parte del agua total que recircula directamente del mar, la filtra mecánicamente, la esteriliza con rayos ultravioletas y la manda a los acuarios.

Los datos utilizados para determinar la calidad del agua de la zona, han sido facilitados por el Instituto Español de Oceanografia, corresponden al año 1996 y a las estaciones 3a, situada frente al emplazamiento del Acuario y a la 3c, situadas frente a la Torre de Hércules.

Las Tablas de Marea utilizadas son las facilitadas por el Puerto de La Coruña para el año 1997.

Los tres millones y medio de litros que son tratados, pasan por los filtros mecánicos y por la batería de rayos ultravioleta cada noventa minutos.
El caudal que es bombeado cada segundo por este circuito es de unos seiscientos cincuenta litros.

Los tres millones y medio de litros de agua de mar son renovados completamente cada treinta y dos horas.

El agua restante no tratada, es renovada completamente a cada marea, a través de unos filtros que impiden la salida de las especies contenidas en la piscina descubierta al mar.

Los equipos de bombeo y filtrado están conectados de tal manera que puedan pararse independientemente, para operaciones de limpieza o mantenimiento, sin perjudicar para nada el funcionamiento total del sistema.

Asimismo, estos mismos equipos están, en buena parte, duplicados para garantizar el funcionamiento ante fallos. También está previsto el tratamiento de la instalación para combatir las adherencias de especies en el interior de los conductos de distribución.

El chorro de agua distintivo tiene una altura equivalente a un edificio de más de doce pisos, es decir, cincuenta metros.

La bomba de agua precisa para lanzar este chorro tiene una potencia de cien kilovatios.

Las instalaciones museográficas disponen de más de ochenta módulos, con dimensiones muy variadas, en los que el visitante debe realizar diferentes acciones. En cincuenta y cinco de estos módulos el visitante debe interaccionar con el mismo y realizar algún tipo de control o dar algún tipo de instrucción.

De entre estos módulos hay una piscina intermareal conectada al mar y con un pantalán flotante para realizar su visita.

Una piscina de más de tres millones de litros que es visitada desde el centro por medio de una sala sumergida con capacidad para unas setenta personas. El frontal acristalado presente en esta sala supera los cincuenta metros lineales.

Un acuario de doscientos cincuenta mil litros de capacidad. Ocho acuarios de más de cinco mil litros de capacidad, con un volumen total de agua de doscientos cincuenta mil litros, están situados dentro de la sala. En total estos acuarios dan un frontal acristalado de otros cincuenta metros de fachada.

Dieciséis acuarios de entre mil y cinco mil litros están situados también dentro de la sala, acompañados de otros once acuarios de menos de mil litros.

Otros cuatro acuarios están situados en la sala de exposi- 
ciones temporales; en total estamos hablando de treinta y ocho acuarios de diferentes capacidades.

Veinte de los módulos están dotados de algún tipo de mecanismo que hace que la situación del mismo no sea estática, sino dinámica.

Cuatro de ellos presentan un audiovisual de mayor o menor tamaño.

En treinta y tres de los módulos hay instalado un ordenador. Ello viene determinado por la utilización de un sistema de señalización dinámica de los acuarios.

En los acuarios que describen un ecosistema, o una zona de costa, la identificación de las especies se realiza por medio de películas en movimiento de las mismas, películas que han sido colocadas en un ordenador.
Existe un laboratorio para la filmación y el montaje informático de las películas de identificación.

Se realiza el cultivo del fitoplancton y del zooplancton necesario para alimentar determinadas especies, en las mismas instalaciones del Acuario. Ello se hace a partir de las semillas que se obtienen de laboratorios exteriores.

Hay unas cincuenta especies vegetales distintas, convenientemente identificadas y señalizadas, procedentes todas del litoral altántico de Galicia.

Un dominio de Internet con una dirección propia ofrece información actualizada cada quince días, durante la fase de construcción del Acuario. (www.casaciencias.org)

El Acuario posee los laboratorios de análisis y cuidado de especies necesarios para un buen funcionamiento.

\section{EQUIPO REDACTOR DEL PROYECTO}

Coordinador General (NECSO)

Proyecto Arquitectónico y Urbanístico (AEPO)

Dirección del Proyecto

Equipo de Arquitectura

Equipo de Instalaciones

Equipo de Estructuras
Arturo de Lorenzo González, Arquitecto

José Manuel Barrio Losada, Arquitecto

Miguel Valverde González, Arquitecto

Francisco de Benita Harguindey, Arquitecto

Carmen Argamentería Cobos, Arquitecto

Matilde Vergara González, Arquitecto

Carmen Cruz Ramírez, Arquitecto Técnico

Rafael Abati García-Manso, Ingeniero de ICAI Alfredo Lozano Rodriguez, Ingeniero Industrial Enrique Sánchez Adán, Delineante Proyectista

Lorenzo Muzas Labad, Ingeniero de Caminos José Ángel Hidalgo González, Ingeniero de Caminos Miguel Fe Marqués, Ingeniero de Caminos - Geotécnico José Rego, Aparejador

Carlos Puig Mestres, Ing. Técnico Industrial

Director del Proyecto

Coordinador Definición de

Especies y Poblaciones
Ramón Bassols Dorr, Biólogo 
Jorge Puig Bargalló, Arquitecto

Definición de Especies y

Poblaciones

Definición Calidad de la Aguas

Proyecto de Tratamiento de Aguas

(Ingeniería Cultural - NECSO)

Definición Teórica Sistema Básico

de Tratamiento de Aguas

Cálculo de la Instalación de

Tratamiento de Aguas
Ricardo Arnaiz Ibarrondo, Biólogo

Enrique Poza Dominguez, Biólogo

Joaquín Villoch Villoch, Biólogo

Antonio M. Grau Jofré, Biólogo

Francisco Riera Munuera, Biólogo

Lourdes Reig Puig, Bióloga

Juan Oca i Baradad, Dr. Ing. Agrónomo

José Ignacio Cura Urquía, Ing. Industrial

Asimismo han participado en la definición del Proyecto, en aspectos referidos a su actividad, los Departamentos Técnicos de las Empresas:

Delegación de Galicia de NECSO ENTRECANALES CUBIERTAS, S.A.

Ingeniería Cultural S.A.

AEPO INGENIEROS CONSULTORES, S.A.

División de Aguas de NECSO ENTRECANALES CUBIERTAS, S.A.

L'Aquarium de Barcelona

Además se ha contado con el asesoramiento y colaboración extraordinaria del Acuario de Monterrey, de EE UU 